\title{
Susceptibility of Colombian Plasmodium falciparum isolates to 4-aminoquinolines and the definition of amodiaquine resistance in vitro
}

\author{
Diego F Echeverry+ ${ }^{+}$Claribel Murillo, Piedad Restrepo P, Lyda O sorio
}

International Center for Medical Research and Training, Cideim, Av. 1N 3-03, Cali, Colombia

There are wide variations in the threshold used to define in vitro resistance of Plasmodium falciparum to amodiaquine $(A Q)$, probably due to differences in methodology and interpretation. In vitro susceptibility data of Colombian P. falciparum strains to $A Q$ and $N$-desethylamodiaquine is used to illustrate the need to standardized methodologies and compare inhibitory concentrations, instead of resistant/susceptible phenotypes, when studying the mechanisms of resistance to $A Q$ and monitoring drug susceptibility trends in the field.

Key words: chloroquine - amodiaquine - N-desethylamodiaquine - in vitro tests

Amodiaquine (AQ) is an antimalarial compound chemically and functionally related to chloroquine (CQ) (Hyde 2002). Currently, it is used (in combination with other antimalarials) as the first choice to treat uncomplicated Plasmodium falciparum malaria in some countries in Africa and South America (Brasseur et al. 1999, WHO 2001). In the body, AQ is rapidly metabolized by the hepatic cytochrome CYP2C8 to N-desethylamodiaquine (DAQ) (Li et al. 2002) which exerts the main antimalarial therapeutic effect (Churchill et al. 1985, Basco \& Le Bras 1993). Unfortunately, as with most antimalarial drugs, in vivo therapeutic failures as well as in vitro resistance of $P$. falciparum to AQ have been reported (Olliaro \& Mussano 2003). A methodology to assess the therapeutic efficacy of most antimalarials has been standardized. In contrast, there are wide variations in the methods used for in vitro testing and particularly for $\mathrm{AQ}$.

The schizonts maturation and radioisotopic microtests are the two most frequently used methods for the in vitro evaluation of antimalarial drugs. The former is based on the microscopical assessment of the inhibition of schizonts maturation in the presence of different drug concentrations. The latter measures the incorporation of radio-marked hypoxanthine by live parasites exposed to different drug concentrations. Other two methods, based on ELISA ( $\mathrm{pLDH}$ and HRP2), are in an advanced process of standardization (Noedl et al. 2003).

The in vitro susceptibility of malaria parasites to a pharmacological compound could be determined using the IC99, IC90, and the IC50 (IC: inhibitory concentration). The latter is defined as the concentration of the drug able to inhibit the growth of $50 \%$ of the parasites with respect to the control without drug, and is the most commonly used. Among others, factors such as percent of red blood cell parasited, hematocrit, the level of plas-

Financial support: OPS, CNT0400132.002

${ }^{+}$Corresponding author: difereg@ cideim.org.co. Young researcher from Colciencias

Received 26 January 2006

Accepted 24 April 2006 matic proteins, and traces of antimalarial drugs in plasma affect the estimation of the ICs (Winstanley \& Watkins 1992). The immune response with antibodies apparently do not play a significant role in the in vitro response to $A Q$, when the hematocrit levels are $<5 \%$ (Wensdorfer \& Paine 1988).

When revising the literature, in spite of the differences found in the in vitro protocols, it seems that there is a consensus on the threshold to define resistance to DAQ ( $\geq 60 \mathrm{nM}$ ) (Ringwald et al. 1996, 2000, Brasseur et al. 1999, Aubouy et al. 2004). However, we found no standard criterion that defines resistance or susceptibility to AQ. In fact, the reported resistance thresholds for AQ vary from 4 to $400 \mathrm{nM}$ (Table I).

The differences in the reported thresholds to define AQ resistance in vitro described in Table I could be partially explained by: (1) variations in the in vitro methodology such as incubation time of the parasite with the drug (from 24 to 50 h) (Childs et al. 1989, Reynes et al. 1997, Pradines et al. 1998, Chaparro \& Wassermann 1999, Basco et al. 2002, Rason et al. 2002), the final hematocrit (from 1 to $1.5 \%$ ) (Childs et al. 1989, Chaparro \& Wassermann 1999), and the percent of red blood cell parasited (from 0.1 to $0.8 \%$ ) (Pradines et al. 1998, Duraisingh et al. 1999, Basco et al. 2002); the most important parameter probably being the hematocrit, since the 4-aminoquinolines have the likeness to concentrate inside erythrocytes (Pussard et al. 1987, Winstanley et al. 1987); (2) the in vitro tests are performed with DAQ but the conclusions refer to AQ (Ringwald et al. 2000, Basco et al. 2002, Aubouy et al 2004); (3) the use of different commercial presentations of AQ without taking into account their different molecular weights (AQ base, AQ hydrochloride or AQ dihydrochloride); and (4) the use of parasites adapted to cultures in vitro and with incubation time $>24 \mathrm{~h}$ are likely to show different results from those obtained with fresh isolates (W Wernsdorfer, pers. commun.).

In our lab, the susceptibility to AQ and DAQ of $22 P$. falciparum Colombian isolates and two reference strains (W2 and D6, resistant and sensitive to CQ respectively) was determined using the radioisotopic method (Desjardins et al. 1979, Cerutti et al. 1997). The isolates that had been kept frozen in liquid Nitrogen were thawed 
following the methodology described by Cerutti et al. (1997) and maintained in continuous culture in supplemented RPMI 1640 (Trager \& Jensen 1976, Desjardins et al. 1979). The samples were synchronized with Sorbitol $1 \%$ (Cerutti et al. 1997), evaluated with a percent of red blood cells parasited of $0.5 \%$ and a hematocrit of $1.5 \%$ and exposed to concentrations of AQ base (provided by WRA) and DAQ (provided by WHO) ranging from 5 to
$320 \mathrm{nM}$. The final concentration of ${ }^{3}[\mathrm{H}]$ hypoxanthine was $0.5 \mu \mathrm{Ci} /$ well and of albumax was $0.5 \%$. The samples were incubated at $37^{\circ} \mathrm{C}$ for $48 \mathrm{~h}$ (Desjardins et al. 1979 , Cerutti et al 1997); each assay was done by duplicate. The counts per minute $(\mathrm{cpm})$ were measured in a scintillation counter (Beckman LS7500) and the IC50 and IC99 were calculated using the PROBIT program in SPSS 7.5 for windows 98 (SPSS. Inc., Chicago 1996).

TABLE I

Thresholds used to define in vitro resistance of Plasmodium falciparum to amodiaquine

\begin{tabular}{|c|c|c|}
\hline Threshold & Method & Reference \\
\hline $\mathrm{IC}_{50} \geq 0.004 \mathrm{mM}(\mathbf{4} \mathbf{n M})$ & Isotopic & Chaparro \& Wasserman 1999 \\
\hline $\mathrm{IC}_{50}^{50} \geq \mathbf{3 0} \mathbf{n M}$ & Schizont maturation & Childs et al. 1989 \\
\hline $\mathrm{IC}_{50} \geq \mathbf{5 9} \mathbf{n M}$ & Isotopic & Basco et al. 2002 \\
\hline $\mathrm{IC}_{50} \geq 60 \mathbf{n M}$ & Isotopic & Reynes et al. 1997 \\
\hline $\mathrm{IC}_{50} \geq 80 \mathbf{n M}$ & Isotopic & Pradines et al. 1998, Rason et al. 2002 \\
\hline & Schizont maturation & Ringwald et al. 1996 \\
\hline $\mathrm{IC}_{50} \geq 0.4 \mathrm{mM} / 1(400 \mathbf{n M})$ & Schizont maturation & Segurado et al. 1997 \\
\hline MIC $\geq 0.4 \mathrm{mMol} / \mathrm{l}$ of blood $(\mathbf{4 0 0} \mathbf{n M})$ & Schizont maturation & Draper et al. 1988 \\
\hline $\begin{array}{l}\mathrm{IC}_{90} \geq 400 \mathrm{nMol} / 1 \text { blood }(400 \mathbf{n M}) \\
\text { in non-immune populations } \\
\mathrm{IC}_{99} \geq 400 \mathrm{nM} / 1 \text { blood }(400 \mathbf{n M})\end{array}$ & Schizont maturation & Wernsdorfer \& Paine 1988 \\
\hline in immune populations & Schizont maturation & Wernsdorfer \& Paine 1988 \\
\hline
\end{tabular}

TABLE II

Amodiaquine (AQ) and desethylamodiaquine (DAQ) inhibitory concentrations (IC) in Plasmodium falciparum Colombian and two reference strains (samples with $\mathrm{IC}_{50}$ of $\mathrm{AQ} \geq 30 \mathrm{nM}$ and $\mathrm{DAQ} \geq 60 \mathrm{nM}$ are highlighted)

\begin{tabular}{|c|c|c|c|c|c|}
\hline $\begin{array}{l}\text { Reference } \\
\text { Strains }\end{array}$ & $\begin{array}{r}\text { AQ } \\
\text { IC50 }\end{array}$ & $\begin{array}{r}\text { DAQ } \\
\text { IC50 }\end{array}$ & $\begin{array}{r}\text { DAQ/ } \\
\text { AQ ratio } \\
\text { IC50 }\end{array}$ & $\begin{array}{r}\text { AQ } \\
\text { IC99 }\end{array}$ & $\begin{array}{r}\text { DAQ } \\
\text { IC99 }\end{array}$ \\
\hline W2 & 21.3 & 145.6 & 6.8 & 77.6 & 1120.9 \\
\hline D6 & 9.4 & 25.3 & 2.6 & 50.2 & 106.4 \\
\hline \multicolumn{6}{|l|}{$\underline{\text { Field strains }}$} \\
\hline Q1114 & 9.6 & 47.5 & 4.9 & 45.8 & 142.4 \\
\hline Q1147 & 30.0 & 125.1 & 4.1 & 230. & 501.5 \\
\hline Q1306 & 34.4 & 122.7 & 3.5 & 200.5 & 696.2 \\
\hline Q1266 & 14.2 & 51.8 & 3.6 & 255.0 & 2294.9 \\
\hline TA7519 & 25.7 & 71.4 & 2.7 & 150.6 & 707.2 \\
\hline TA7529 & 13.2 & 62.7 & 4.7 & 97.7 & 650.0 \\
\hline TA4609 & 26.7 & 79.7 & 2.9 & 217.2 & 346.9 \\
\hline TA6182 & 26.7 & 177.5 & 6.6 & 173.1 & 4308.0 \\
\hline TA4641 & 23.0 & 38.3 & 1.6 & 128.3 & 367.4 \\
\hline TA4640 & 20.1 & 86.0 & 4.2 & 216.8 & 1060.3 \\
\hline TA10254 & 30.5 & 111.8 & 3.6 & 53.8 & 230.4 \\
\hline TU384F & 13.1 & 62.4 & 4.7 & 55.1 & 156.9 \\
\hline TU9288 & 27.2 & 69.9 & 2.5 & 52.5 & 547.8 \\
\hline TU741 & 41.0 & 355. & 8.6 & 845.2 & 4783.9 \\
\hline TU545F & 18.4 & 159.9 & 8.6 & 77.1 & 330.7 \\
\hline TU9255 & 22.2 & 101.5 & 4.5 & 189.7 & 530.9 \\
\hline TU8064 & 11.6 & 39.5 & 3.3 & 105.1 & 493.6 \\
\hline TU11365F & 39.6 & 222.3 & 5.6 & 237.8 & 16281.9 \\
\hline CA2855 & 64.6 & 198.0 & 3.0 & 225.1 & 2831.4 \\
\hline BV5029 & 37.1 & 122.4 & 3. & 161.9 & 286.8 \\
\hline BV5029F & 33.3 & 94.8 & 2.8 & 316.1 & 968.6 \\
\hline BV5037 & 30.7 & 94.2 & 3.0 & 126.2 & 449.2 \\
\hline Mean & 27.0 & 113.4 & 4.2 & 189.1 & 1771.2 \\
\hline SD & 12.4 & 74.0 & 1.8 & 164.9 & 3492.1 \\
\hline
\end{tabular}

SD: standard deviation 
In the Colombian strains, the mean DAQ IC50 (113.45 $\mathrm{nM})$ was 4.25 times higher than the one for AQ $(27 \mathrm{nM})$. The IC50 results of $\mathrm{W} 2$ and $\mathrm{D} 6$ also followed this pattern (Table II). The mean DAQ and AQ IC99 of the field isolates $(1771.27 \mathrm{nM}$ and $189.17 \mathrm{nM}$, respectively) were well above the IC99s reported by Childs et al. (1989) in samples from Thailand (157 $\mathrm{nM}$ and 46,7 nM, respectively). The relatively high IC99s of Colombian isolates suggests the presence of AQ and DAQ resistance. However, our and Child's study used different methodologies (culture vs fresh isolates, and radioisotopic vs schizont maturation method) making them difficult to compare. Looking at Table I, the thresholds to define AQ resistance as IC50 > $60 \mathrm{nM}$ (the proposed threshold for DAQ) contradict our findings and reports showing that $\mathrm{AQ}$ is three times more potent than DAQ (Pussard et al. 1987, Winstanley et al. 1987, 1990). Hence, the threshold to define AQ resistance should be lower than the one described for DAQ (Churchill et al. 1985, Childs et al. 1989).

When in vitro resistance to DAQ and AQ is defined as an IC50 $\geq 60 \mathrm{nM}$ and $\geq 30 \mathrm{nM}$ respectively, 82\% (18/22) field isolates were resistant to DAQ and $41 \%$ (9/22) to $\mathrm{AQ}$. All samples that were resistant to AQ were also resistant to DAQ but not all samples resistant to DAQ were resistant to $\mathrm{AQ}$, which does not support the statement that resistance to DAQ predicts resistance to AQ (Basco et al. 2002, Aubouy et al. 2004). In fact, samples (including W2 strain) with DAQ IC50 > $120 \mathrm{nM}$ (twice the defined threshold) showed AQ IC50 below $30 \mathrm{nM}$. The IC50 values of AQ and DAQ are highly correlated (Pearson $\mathrm{r}=$ $0,736 \mathrm{P}<0.001)$ suggesting that the inconsistencies in defining resistance could be explained by inaccurate thresholds. In fact, a linear regression analysis with log transformed data showed that, in this dataset, the DAQ IC50 $60 \mathrm{nM}$ was equivalent to AQ IC50 $15.48 \mathrm{nM}$. This AQ IC50 will classify eight more of our isolates as AQ resistant. For AQ IC50 $30 \mathrm{nM}$ the equivalent DAQ IC50 was $119.28 \mathrm{nM}$, consistent with the threshold proposed by Childs et al. (1989) to define resistance to AQ (Childs et al. 1989). Based on this data, AQ IC50 values between $15 \mathrm{nM}$ and $30 \mathrm{nM}$ could be used to identify mutations or copy numbers associated with AQ resistance using a similar approach to that of Price et al. (2004) for mefloquine resistance. Nevertheless, this assumes that the $60 \mathrm{nM}$ threshold used to define in vitro DAQ resistance is accurate, which is not necessarily true.

Pharmacokinetic and pharmacodynamic studies help to orientate the definition of a sensitive/resistance in vitro threshold to antimalarial drugs and should be expanded. In the meantime, it will be helpful to standardize methodologies and use continuous in vitro data (i.e. ICs rather than resistant/susceptible phenotypes) in studies dealing with the identification of the mechanisms of resistance to AQ and monitoring drug susceptibility trends in the field. In public health it is probably more relevant to monitor in vitro resistance to DAQ instead of AQ, since DAQ exerts the major antimalarial activity in vivo. On the other hand, understanding the mechanism of resistance to AQ would be useful in the design of new drugs, particularly 4-aminoquinoline derivatives.

\section{REFERENCES}

Aubouy A, Mayombo J, Keundjian A, Bakary M, Le Bras J, Deloron P 2004. Short report: lack of prediction of amodiaquine efficacy in treating Plasmodium falciparum malaria by in vitro tests. Am J Trop Med Hyg 71: 294-296.

Basco LK, Le Bras J 1993. In vitro activity of monodesethylamodiaquine and amopyroquine against African isolates and clones of Plasmodium falciparum. Am J Trop Med Hyg 48: 120-125.

Basco LK, Ndounga M, Tejiokem M, Ngane VF, Youmba JC, Ringwald P, Soula G 2002. Molecular epidemiology of malaria in Cameroon. XI. Geographic distribution of Plasmodium falciparum isolates with dihydrofolate reductase gene mutations in southern and central Cameroon. Am J Trop Med Hyg 67: 378-382.

Brasseur P, Guiguemde R, Diallo S, Guiyedi V, Kombila M, Ringwald P, Olliaro P 1999. Amodiaquine remains effective for treating uncomplicated malaria in west and central Africa. Trans $R$ Soc Trop Med Hyg 93: 645-650.

Cerutti Junior C, Marques C, Alencar FE, Durlacher RR, Alween A, Segurado AA, Pang LW, Zalis MG 1999. Antimalarial drug susceptibility testing of Plasmodium falciparum in Brazil using a radioisotope method. Mem Inst Oswaldo Cruz. 94: 803-809.

Chaparro J, Wassermann M 1999. Comparación de técnicas in vitro para detectar resistencia de Plasmodium falciparum a medicamentos. Biomédica 19: 103-114.

Childs GE, Boudreau EF, Milhous WK, Wimonwattratee T, Pooyindee N, Pang L, Davidson Jr. DE 1989. A comparison of the in vitro activities of amodiaquine and desethylamodiaquine against isolates of Plasmodium falciparum. Am J Trop Med Hyg 40: 7-11.

Churchill FC, Patchen LC, Campbell CC, Schwartz IK, NguyenDinh P, Dickinson CM 1985. Amodiaquine as a prodrug: importance of metabolite(s) in the antimalarial effect of amodiaquine in humans. Life Sci 36: 53-62.

Desjardins RE, Canfield CJ, Haynes JD, Chulay JD 1979. Quantitative assessment of antimalarial activity in vitro by a semiautomated microdilution technique. Antimicrob Agents Chemother 16: 710-718.

Draper CC, Hills M, Kilimali VA, Brubaker G 1988. Serial studies on the evolution of drug resistance in malaria in an area of east Africa: findings from 1979 up to 1986. Am J Trop Med Hyg 91: 265-273.

Duraisingh MT, Jones P, Sambou I, von Seidlein L, Pinder M, Warhurst DC 1999. Inoculum effect leads to overestimation of in vitro resistance for artemisinin derivatives and standard antimalarials: a Gambian field study. Parasitology 119 (Pt 5): 435-440.

Hyde JE 2002. Mechanisms of resistance of Plasmodium falciparum to antimalarial drugs. Microb Infect 4: 165-174.

Li XQ, Bjorkman A, Andersson TB, Ridderstrom M, Masimirembwa CM 2002. Amodiaquine clearance and its metabolism to $\mathrm{N}$-desethylamodiaquine is mediated by CYP2C8: a new high affinity and turnover enzyme-specific probe substrate. J Pharmacol Exp Ther 300: 399-407.

Noedl H, Wongsrichanalai C, Wernsdorfer WH 2003. Malaria drug-sensitivity testing: new assays, new perspectives. Trends Parasitol 19: 175-181. 
Olliaro P, Mussano P 2003. Amodiaquine for treating malaria. Cochrane Database Syst Rev: CD000016.

Pradines B, Tall A, Parzy D, Spiegel A, Fusai T, Hienne R, Trape JF, Doury JC 1998. In-vitro activity of pyronaridine and amodiaquine against African isolates (Senegal) of Plasmodium falciparum in comparison with standard antimalarial agents. J Antimicrob Chemother 42: 333-339.

Price RN, Uhlemann AC, Brockman A, McGready R, Ashley E, Phaipun L, Patel R, Laing K, Looareesuwan S, White NJ, Nosten F, Krishna S 2004. Mefloquine resistance in Plasmodium falciparum and increased pfmdr1 gene copy number. Lancet 364: 438-447.

Pussard E, Verdier F, Faurisson F, Scherrmann JM, Le Bras J, Blayo MC 1987. Disposition of monodesethylamodiaquine after a single oral dose of amodiaquine and three regimens for prophylaxis against Plasmodium falciparum malaria. Eur J Clin Pharmacol 33: 409-414.

Rason MA, Ariey F, Rafidimanantsoa L, Andrianantenaina BH, Sahondra Harisoa JL, Randrianarivelojosia M 2002. Monitoring the drug-sensitivity of Plasmodium falciparum in coastal towns in Madagascar by use of in vitro chemosensitivity and mutation detection tests. Parasite 9: 247-253.

Reynes JM, Fargette J, Gaborit P, Yarde S 1997. In vitro responses of Plasmodium falciparum isolates to five antimalarial drugs in French Guiana during 1994 and 1995. Mem Inst Oswaldo Cruz 92: 251-252.

Ringwald P, Bickii J, Basco LK 1996. In vitro activity of antimalarials against clinical isolates of Plasmodium falciparum in Yaounde, Cameroon. Am J Trop Med Hyg 55: 254-258.
Ringwald P, Keundjian A, Same Ekobo A, Basco LK 2000. Chemoresistance of Plasmodium falciparum in the urban region of Yaounde, Cameroon. Part 2: Evaluation of the efficacy of amodiaquine and sulfadoxine-pyrimethamine combination in the treatment of uncomplicated Plasmodium falciparum malaria in Yaounde, Cameroon. Trop Med Int Health 5: 620-627.

Segurado AA, di Santi SM, Shiroma M 1997. In vivo and in vitro Plasmodium falciparum resistance to chloroquine, amodiaquine and quinine in the Brazilian Amazon. Rev Inst Med Trop São Paulo 39: 85-90.

Trager W, Jensen JB 1976. Human malaria parasites in continuous culture. Science 193: 673-675.

Wernsdorfer WH, Paine D 1988. Drug sensitivity tests in malaria parasites, In Principles and Practices of Malariology, Churchill Livingstone, Edinburgh, p. 1765-1800.

Winstanley P, Edwards G, Orme M, Breckenridge A 1987. The disposition of amodiaquine in man after oral administration. Br J Clin Pharmacol 23: 1-7.

Winstanley PA, Simooya O, Kofi-Ekue JM, Walker O, Salako LA, Edwards G, Orme ML, Breckenridge AM 1990. The disposition of amodiaquine in Zambians and Nigerians with malaria. Br J Clin Pharmacol 29: 695-701.

Winstanley PA, Watkins WM 1992. Pharmacology and parasitology: integrating experimental methods and approaches to falciparum malaria. Br J Clin Pharmacol 33: 575-581.

WHO-World Health Organization 2001. The use of antimalarial drugs. Report of a WHO informal consulation. Roll Back Malaria/WHSi. WHO, Genove. 